\title{
The Effects of Salt Concentration and Foulant Surface Charge on Hydrocarbon Fouling of a Poly(vinylidene fluoride) Microfiltration Membrane
}

Zhengwang He, Sirirat Kasemset ${ }^{1}$, Alon Y. Kirschner, Yu-Heng Cheng, Donald R. Paul, Benny D. Freeman*

Department of Chemical Engineering, Center for Energy and Environmental Resources, and Texas Materials Institute, The University of Texas at Austin, 10100 Burnet Road Building 133, Austin, TX 78758

* Corresponding author (Tel: +1-512-232-2803; Email: freeman@che.utexas.edu)

${ }^{1}$ Current address: Evonik Corporation, 4201 Evonik Road, Theodore, AL 36582

Manuscript prepared for submission to Water Research 


\begin{abstract}
The effects of inorganic salts and organic hydrocarbons on membrane fouling are often investigated independently. However, in many cases, these foulants are commonly found together, and such mixtures are rarely the subject of fouling studies. In this study, crude oil-in-water emulsions were formulated at three different added $\mathrm{NaCl}$ concentrations, $0,10^{-3}$ and $10^{-1} \mathrm{M}$. Surface properties, such as surface tension and surface charge, of these emulsions and a poly(vinylidene fluoride) (PVDF) microfiltration (MF) membrane were characterized. The Derjaguin-Landau-VerweyOverbeek (DLVO) model was utilized to simulate membrane-oil droplet and oil layer-oil droplet surface interactions. The DLVO model qualitatively predicted increasing fouling propensity with increasing emulsion salt concentration. The PVDF MF membrane was challenged with crude oil-in-water emulsions in constant permeate flux crossflow fouling tests to characterize the fouling propensity of the various emulsions, and the results were consistent with the model predictions.
\end{abstract}

\title{
KEYWORDS
}

DLVO model, zeta potential, oil emulsion, ionic strength, membrane fouling, fouling propensity 


\section{INTRODUCTION}

Fouling is a major challenge in membrane processes, such as the filtration of aqueous mixtures containing both hydrocarbons and ionic components (Hesampour et al. 2008). Hydrocarbon molecules are generally hydrophobic, and many commercial polymeric water purification membranes made of poly(vinylidene fluoride) and polysulfone, are intrinsically hydrophobic as well (Geise et al. 2010, Ulbricht 2006). Hydrophobic-hydrophobic interactions between the membrane surface and hydrocarbons are often believed to be a major cause of membrane fouling in filtration of oily water (Baker 2004, Elmaleh and Ghaffor 1996, Howe and Clark 2002, Janknecht et al. 2004). The presence of ionic species in feed mixtures can influence electrostatic interactions between the membrane surfaces, and foulants (Fane et al. 1983, Singh and Song 2005, Vigneswaran and Kwon 2015, Xiao et al. 2011).

The effect of ionic species on fouling is often investigated in the context of biofouling and colloidal fouling (Fane et al. 1983, Singh and Song 2005, Vigneswaran and Kwon 2015, Xiao et al. 2011), and it is rarely studied with hydrocarbon-containing feed streams. In these membrane-foulant systems, the effect of ionic species on fouling has been ascribed to electrostatic screening.

Surface interaction models and short-range interaction force measurements have been used to predict membrane fouling with organic and inorganic colloids (Brant and Childress 2002, Ding et al. 2013, Lee and Elimelech 2006, Tang et al. 2009). Lee and Elimelech (2006) developed an atomic force measurement technique to directly measure the interaction force between a membrane surface and a foulant particle. Tang et al. (2009) measured interaction forces and correlated fouling behavior with membranehumic acid interactions. Brant and Childress (2002) applied the Derjaguin-Landau- 
Verwey-Overbeek (DLVO) and extended DLVO (XDLVO) models to predict the fouling propensity of three RO membranes and three colloidal foulants. The XDLVO model was applied to an MF membrane-protein system by Ding et al. (2013).

However, the influence of salt concentration (or ionic strength) on hydrocarbon fouling has not been quantitatively characterized. Systematic studies of feed streams containing both hydrocarbons and inorganic salts are rarely reported. In this study, a series of fouling mixtures was systematically formulated to isolate the effect of foulant surface charge on membrane fouling. Crude oil-in-water emulsions were used to represent simplified hydrocarbon foulants. Different concentrations of sodium chloride $(\mathrm{NaCl})$ were added to the emulsion to vary foulant surface charge. Therefore, observed differences in fouling behavior with different emulsions can be attributed to foulant surface charge, because foulant size, size distribution, hydrophobicity, and chemistry were maintained relatively constant. A poly(vinylidene fluoride) (PVDF) MF membrane was challenged with crude oil-in-water emulsions in constant permeate flux crossflow fouling tests, and the fouling propensity was evaluated with respect to feed salt concentration. Membrane-oil droplet and oil layer-oil droplet surface interactions were estimated using the DLVO model. The calculated DLVO interaction energies corresponded qualitatively with the observed fouling propensity.

\section{BACKGROUND AND THEORY}

\subsection{Surface tension}

The surface tension, $\gamma$, of a liquid or a solid is the surface free energy per unit area (van Oss 2006, van Oss et al. 1988). The apolar Lifshitz-van der Waals (LW) 
component, $\gamma^{L W}$, and the polar Lewis acid-base (AB) component, $\gamma^{A B}$, are additive components of surface tension: (van Oss 1993, 2006)

$$
\gamma_{i}=\gamma_{i}^{L W}+\gamma_{i}^{A B}
$$

where the subscript " $i$ " denotes a specific material i or phase of a material. The acid-base component can be expressed as a function of the electron-acceptor, $\gamma^{+}$, and electrondonor, $\gamma^{-}$, components: (van Oss 1993, 2006, van Oss et al. 1988)

$$
\gamma_{i}^{A B}=2 \sqrt{\gamma_{i}^{+} \cdot \gamma_{i}^{-}}
$$

For non-polar materials (i.e., $\gamma_{i}^{A B}=0$ ), only the $\mathrm{LW}$ component contributes to the total surface tension (i.e., $\gamma_{i}=\gamma_{i}^{L W}$ ). A more polar material generally has a higher value of $\gamma_{i}^{A B}$ (van Oss et al. 1988).

Contact angle measurements are commonly utilized to characterize surface tension components and interfacial tensions (van Oss 1993, 2006, van Oss et al. 1988). The contact angle, $\theta$, between a solid and a liquid is a function of the surface tensions of the two materials: (van Oss 1993, 2006, van Oss et al. 1988)

$$
(1+\cos \theta) \gamma_{l}=2\left[\sqrt{\gamma_{s}^{L W} \gamma_{l}^{L W}}+\sqrt{\gamma_{s}^{+} \gamma_{l}^{-}}+\sqrt{\gamma_{s}^{-} \gamma_{l}^{+}}\right]
$$

where the subscripts " $l$ " and " $s$ " refer to the liquid and solid phases, respectively. Materials with known surface tensions and surface tension components are often used as reference materials in contact angle measurements (van Oss 1993, 2006, van Oss et al. 1988).

\subsection{Electrokinetic potentials}

Figure 1 illustrates electrokinetic effects at a material-solution interface. The socalled $\psi_{0}$ potential of particles, macromolecules or surfaces is the electrical potential at the interface of the material and the contiguous solution (van Oss 2006). It is, however, 
not directly measureable. The Stern layer is essentially a static layer of hydrated ions surrounding the actual interface, and it is often considered to be a rigid layer (Delgado et al. 2007, Van Wagner 2010). The zeta potential of surface $i, \zeta_{i}$, is the electrical potential at the slipping plane, which is the outer surface of the Stern layer (Probstein 1994, van Oss 2006). Unlike the $\psi_{0}$ potential, the zeta potential can be evaluated by electrokinetic measurements (e.g., electro-osmosis and streaming potential) (van Oss 2006). For practical considerations, the term "zeta potential" is often used interchangeably with "surface charge" (van Oss 2006). 


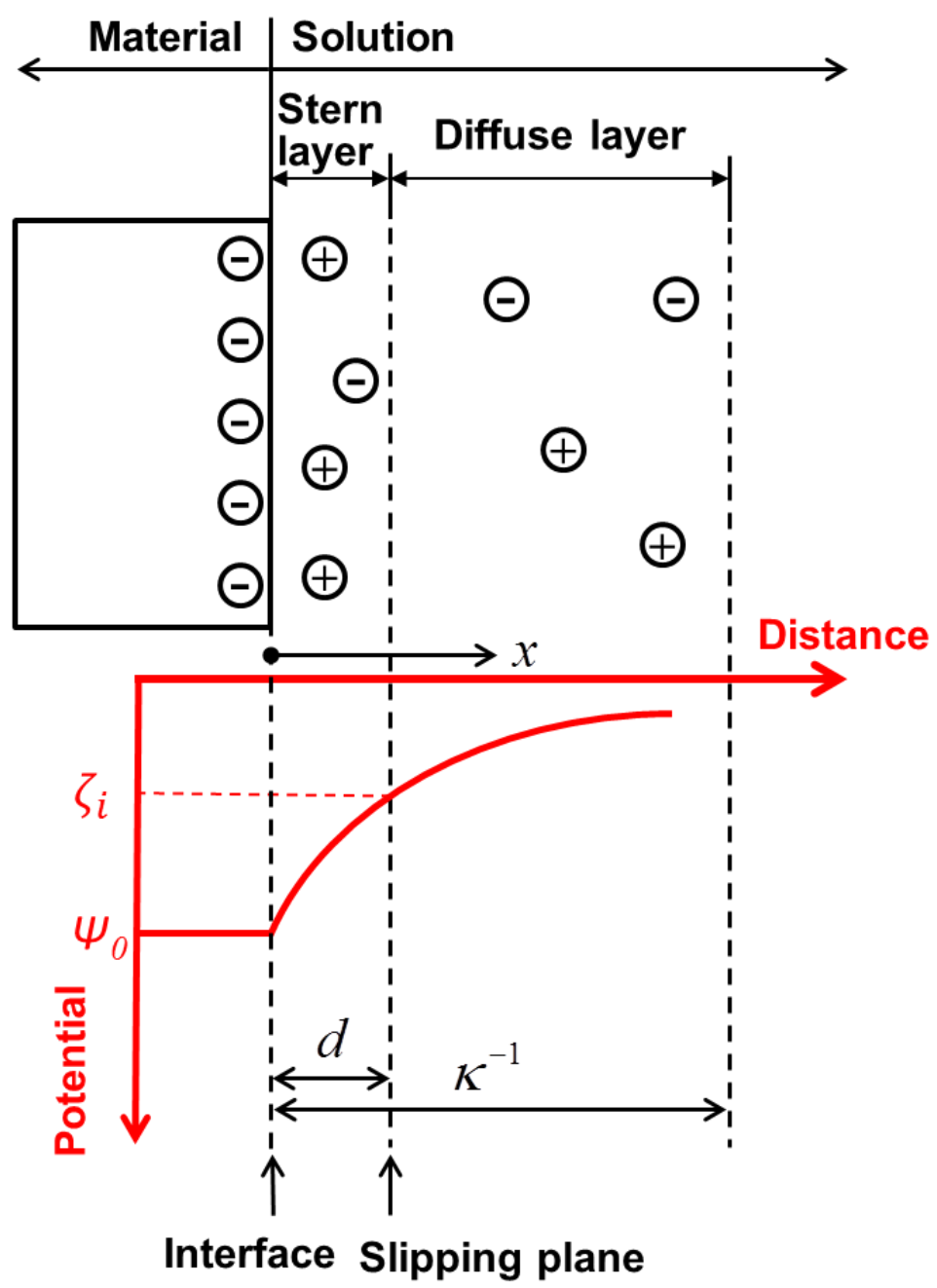

Figure 1. An illustration of electrokinetic potentials at a material-solution interface. The $\psi_{0}$ potential is located at the material-solution interface. The zeta potential of surface i, $\zeta_{i}$, is located at the slipping plane. The electrokinetic potential decays exponentially within the electrical double layer, which consists of the Stern layer and the diffusive layer. (Bard and Faulkner 2001).

The electrokinetic potential decays exponentially within the electrical double layer: (Adamczyk and Warszyński 1996, Poortinga et al. 2002, van Oss 2006)

$$
\psi(x)=\zeta_{i} e^{-\kappa(x-d)}
$$


where $x$ is the distance from material-solution interface, and $d$ is Stern layer thickness. The thickness of the electrical double layer, also known as the Debye screening length, $\kappa^{-1}$, is a function of solution ionic strength, $I$ : (van Oss 2006)

$$
\kappa^{-1}=\sqrt{\frac{\varepsilon_{0} \varepsilon_{r} k T}{2 N_{A} I e^{2}}}
$$

where $\varepsilon_{0} \varepsilon_{r}\left(78.3 \times 8.85 \times 10^{-12} \mathrm{~F} / \mathrm{m}\right)$ is the permittivity of the solution, $k\left(1.38 \times 10^{-23}\right.$ $\mathrm{J} / \mathrm{K})$ is Boltzmann's constant, $T$ is the absolute temperature, $N_{A}$ is Avogadro's number, and $e\left(1.6 \times 10^{-19} \mathrm{C}\right)$ is the electronic charge. Ionic strength, $I$, is defined as follows: (van Oss 2006)

$$
I=\frac{1}{2} \sum c_{i} z_{i}^{2}
$$

where $c_{i}$ is the concentration of ionic species $\mathrm{i}$, and $z_{i}$ is the valence of ionic species $\mathrm{i}$. For a 1:1 electrolyte, such as $\mathrm{NaCl}$ used in this study, the ionic strength numerically equals the salt concentration. Higher ionic strength leads to a thinner electrical double layer (i.e., a smaller $\kappa^{-1}$ ), and the electrokinetic potential decays more rapidly with distance, because the electrolyte in the bulk solution creates an electrical field that overlaps and screens the material's electrical double layer.

Assuming a constant $\psi_{0}$ potential, $\zeta_{i}$ is a function of $\kappa$ :

$$
\zeta_{i}=\psi_{0} e^{-\kappa d}
$$

Consequently, at higher ionic strength, the measured zeta potential deviates more from $\psi_{0}$ than at lower ionic strength. For a material with constant $\psi_{0}$, the measured zeta potential decreases with increasing ionic strength due to such electrostatic screening (van Oss 2006). 


\subsection{The DLVO model}

While many interactions exist between two approaching surfaces, such as the van der Waals (LW) interaction, electrostatic (EL) interaction, hydrophobic interaction, and steric interactions, the Derjaguin-Landau-Verwey-Overbeek (DLVO) model is used to estimate LW and EL interactions.

The total DLVO interaction energy is the sum of the LW and EL interaction energies: (Brant and Childress 2002)

$$
U^{D L V O}=U^{L W}+U^{E L}
$$

where $U^{D L V O}, U^{L W}$ and $U^{E L}$ are the total DLVO interaction energy, LW interaction energy and EL interaction energy, respectively. In the DLVO model, the free energy of adhesion per unit area, $\Delta G$, also contains an LW component, $\Delta G^{L W}$, and an EL component, $\Delta G^{E L}$.

A recent development suggested adding acid-base (AB) interactions to the DLVO model, known as the extended DLVO (XDLVO) model (Brant and Childress 2002, Ding et al. 2013, van Oss 2006). Researchers successfully applied the XDLVO model in applications involving polar surfaces. However, as discussed in detail later, the crude oil in this study was considered non-polar, so the DLVO model was more applicable. In applying the DLVO model, membrane was treated as a flat surface and oil droplets were approximated as perfect spheres and point charges, consistent with previous studies (Aimar and Bacchin 2010, Bacchin et al. 1995, Bacchin et al. 2002, Brant and Childress 2002, Hoek et al. 2003, Muthu et al. 2014). 


\subsubsection{LW interactions}

For an oil droplet approaching a membrane surface in an aqueous solution, $\Delta G^{L W}$ is expressed as a function of the $\gamma^{L W}$ values of the three phases: (Brant and Childress 2002)

$$
\Delta G_{y_{0}}^{L W}=2\left(\sqrt{\gamma_{l}^{L W}}-\sqrt{\gamma_{m}^{L W}}\right)\left(\sqrt{\gamma_{c}^{L W}}-\sqrt{\gamma_{l}^{L W}}\right)
$$

where subscripts " $l$ ", " $m$ " and " $c$ " represent the aqueous liquid phase, the membrane and the oil droplet (crude oil in our case), respectively. The membrane can be approximated as an infinite flat plate, and the oil droplet is treated as a sphere. Using this idealized sphere-plate geometry, the membrane and oil droplet LW interaction energy in an aqueous environment, $U^{L W}$, is: (Brant and Childress 2002)

$$
U^{L W}=2 \pi \Delta G_{y_{0}}^{L W} \frac{y_{0}^{2} a_{c}}{h}
$$

where $a_{c}$ is the oil droplet radius, $h$ is separation distance between the membrane surface and the oil droplet, and $y_{0}$ is a hypothetical minimal equilibrium cut-off distance, where two surfaces are viewed as being in contact with one another. Typically, $y_{0}$ has an assigned value of $0.158 \mathrm{~nm}$ (Brant and Childress 2002).

\subsubsection{EL interactions}

$U^{E L}$ can be calculated for three scenarios: constant potential, constant surface charge, or an intermediate case given by a linear superposition approximation (LSA) (Lin and Wiesner 2010). For most realistic systems, the LSA assumption is the more appropriate approximation (Gregory 1975, Lin and Wiesner 2010, Petosa et al. 2010). In this study, the LSA equation was used to calculate the EL interaction energy. For a sphere-plate system, exact analytical expressions for the EL interaction energy under the LSA assumption were recently developed by Lin and Wiesner (2012): 


$$
U^{E L}=U_{S P}^{E L}(h)+U_{S P}^{E L}\left(h+2 a_{c}\right)+O
$$

where $U_{S P}^{E L}$ is identical to an approximate sphere-plate system EL interaction energy based on the Derjaguin approximation (Lin and Wiesner 2010, Petosa et al. 2010), and $O$ is a correction term. Explicit expressions for the terms in Equation [11] are: (Lin and Wiesner 2010)

$$
\begin{aligned}
& U_{S P}^{E L}(h)=64 \pi \varepsilon_{0} \varepsilon_{r} a_{c}\left(\frac{k_{B} T}{z e}\right)^{2} \Gamma_{m} \Gamma_{c} e^{-\kappa h} \\
& O=\frac{64 \pi \varepsilon_{r} \varepsilon_{0}}{\kappa}\left(\frac{k_{B} T}{z e}\right)^{2} \Gamma_{m} \Gamma_{c}\left[-e^{-\kappa h}+e^{-\kappa\left(h+2 a_{c}\right)}\right] \\
& \Gamma_{i}=\tanh \left(\frac{z e \zeta_{i}}{4 k_{B} T}\right)
\end{aligned}
$$

where $\zeta_{m}$ and $\zeta_{c}$ are zeta potentials of the membrane and the crude oil droplet, respectively. When $\kappa a_{c}>1$ and $a_{c}>h$, such as in the case of the oil emulsions and separation distances considered in this study, $U_{S P}^{E L}(h)$ is the dominant contribution to the EL interaction energy (Lin and Wiesner 2010).

\section{Materials ANd Methods}

\subsection{Materials}

Flat sheet PVDF microfiltration membranes with a nominal pore size of $0.2 \mu \mathrm{m}$ were generously supplied by Pall Corporation (Port Washington, NY). Membranes were pretreated by soaking in ethanol for one hour and then stored in ultrapure water for at least one hour until needed for experiments.

Pennsylvanian grade light crude oil was kindly provided by American Refining Group (Bradford, PA). Triton ${ }^{\mathrm{TM}}$ X-100 (a non-ionic surfactant), sodium chloride, sodium hydroxide aqueous solution $(0.1 \mathrm{M})$, hydrochloric acid aqueous solution $(0.1 \mathrm{M})$, 
diiodomethane and ethylene glycol were purchased from Sigma Aldrich (St. Louis, MO). Denatured ethanol was purchased from Fisher Scientific (Fairlawn, NJ). Style 8764 virgin grade polytetrafluoroethylene (PTFE) flat sheets were obtained from Technetics Group (Houston, TX). Ultrapure water (18.2M $\Omega-\mathrm{cm}$ and $5.4 \mathrm{ppb}$ TOC) was produced by a Millipore RiOs and a Milli-Q lab water system (Billerica, MA). Aqueous sodium chloride conductivity standards of various concentrations were purchased from RICCA Chemical Company (Dear Park, TX). All chemicals were used as received.

\subsection{Model foulant formulation and characterization}

Crude oil-in-water emulsions were prepared using a crude oil-to-surfactant mass ratio of 8:2 and a total oil plus surfactant concentration of $200 \mathrm{ppm}$. Emulsion-0 refers to the emulsion with no added salt, Emulsion-1 refers to the emulsion with $10^{-1} \mathrm{M}$ added salt, and Emulsion-3 refers to the emulsion with $10^{-3} \mathrm{M}$ added salt.

Nominally, 8 L of crude oil-in-water emulsion was prepared for a crossflow fouling test. Crude oil (1.28 g) and surfactant (0.32 g) were first measured into a centrifuge tube and mixed using a vortex mixer (Fisher Scientific, Fairlawn, NJ). The oil/surfactant mixture, together with $2 \mathrm{~L}$ of ultrapure water, was then transferred to a Waring $^{\circledR}$ laboratory blender and blended at 20,000 rpm for 5 minutes to produce a concentrated emulsion. To produce the final emulsion, ultrapure water $(3 \mathrm{~L})$ was added to the feed tank of the crossflow fouling system, followed by the concentrated emulsion, and then another $3 \mathrm{~L}$ of ultrapure water.

Emulsion-1 and Emulsion-3 were prepared by adding $\mathrm{NaCl}$, while maintaining the same hydrocarbon concentration. The preparation procedure was modified slightly relative to the previous procedure. The concentrated emulsion was prepared to have the same salt concentration as that of the final emulsion to minimize any potential effects of 
salt concentration fluctuation on emulsion stability (Binks et al. 2006). To produce the final emulsion, $\mathrm{NaCl}$ was first dissolved in the feed tank of the crossflow fouling system with ultrapure water $(3 \mathrm{~L})$. Then, the concentrated emulsion was added to the feed tank, and finally another $3 \mathrm{~L}$ of ultrapure water was added.

An Oakton CON110 conductivity meter (Vernon Hills, IL) was calibrated with sodium chloride conductivity standards before measuring emulsion conductivity. The $\mathrm{pH}$ of emulsions was measured with an Oakton pH110 meter (Vernon Hills, IL). Zeta potentials of emulsions were measured with a Zetasizer Nano (Malvern, UK) using DTS1070 cells at $25^{\circ} \mathrm{C}$. At least three measurements were performed for each emulsion.

\subsection{Membrane zeta potential measurement}

Membrane zeta potentials were measured with a SurPASS electrokinetic analyzer (Anton Paar, Ashland, VA). Although potassium chloride is commonly used as the background electrolyte, we chose to use sodium chloride so that the ionic species were identical to that of the formulated oil emulsions. Fresh aqueous sodium chloride solutions of various concentrations (i.e., 1, 5, 10, 20 and $50 \mathrm{mM}$ ) were used as the background solution. The electrolyte solution $\mathrm{pH}$ was adjusted with a sodium hydroxide solution $(0.1$ M) to reach a $\mathrm{pH}$ above 9 at the beginning of a measurement. The instrument adjusted the electrolyte solution $\mathrm{pH}$ by auto-titrating with a hydrochloric acid aqueous solution $(0.1$ $\mathrm{M})$, and the zeta potential was measured over the $\mathrm{pH}$ range from 9 to 4 .

Two flat sheet membrane samples, $55 \mathrm{~mm} \times 25 \mathrm{~mm}$, were separated by two polypropylene spacers to form a flow channel. One of the membrane samples was punched with two holes aligned with the flow channel to allow flow into and out of the clamping cell. The clamping cell configuration allows the electrolyte solution to flow tangentially across the membrane surface to avoid potential influences of specific ion 
adsorption inside the membrane porous structure (Fievet et al. 2001). The applied pressure was $300 \mathrm{mBar}$.

\subsection{Surface tension measurements}

Contact angle measurements were performed using a Ramé-Hart (Succasunna, NJ) Model 200 goniometer at room temperature. The surface tension and surface tension components of the crude oil and the PVDF membrane were calculated from these measurements.

The total surface tension of the crude oil, $\gamma_{c}$, was measured using the pendant drop technique (Hansen and Rødsrud 1991, Saad et al. 2011, Stauffer 1965). A drop of crude oil was dispensed by a Gilmont ${ }^{\circledR}$ micrometer syringe (Cole Parmer, Vernon Hills, IL). The drop was hanging freely from the needle tip when a measurement was taken. The stainless steel needle (solid), oil (liquid), and surrounding air (vapor) formed a threephase equilibrium. The DROPimage software supplied with the goniometer calculated the liquid phase surface tension using the Laplace-Young equation and the known surface tensions of the solid and vapor phases (Arashiro and Demarquette 1999, Ramesh Babu 1986).

The crude oil LW surface tension component, $\gamma_{c}^{L W}$, was estimated based on its sessile drop contact angle, $\theta_{S}$, with respect to a flat sheet of PTFE. PTFE is often used as a reference material because the acid-base contribution to the total surface energy of PTFE is zero (i.e., $\gamma_{P T F E}^{A B}=0$ ), so only the LW component contributes to the total surface energy (cf., Equation [1]) (Busscher and Arends 1981). Therefore, a simplified form of Equation [3] can be applied to estimate $\gamma_{c}^{L W}$ : (Busscher and Arends 1981)

$$
\gamma_{c}^{L W}=\gamma_{l}^{L W}=\frac{\left(1+\cos \theta_{S}\right)^{2} \gamma_{l}^{2}}{4 \gamma_{s}^{L W}}
$$


where the liquid phase $l$ refers to the crude oil, and the solid phase $s$ refers to the PTFE flat sheet.

The surface tension of the PVDF membrane was estimated based on captive bubble contact angle, $\theta_{C}$, measurements. The captive bubble method was used because the solvent could penetrate and spread on the membrane surface in a sessile drop set-up. The membrane was immersed in the selected liquids, and an air bubble was placed below the membrane. The contact angle was measured through the reference liquid. The contact angle equation (cf., Equation [3]) has three independent variables, $\gamma_{s}^{L W}, \gamma_{s}^{+}$and $\gamma_{s}^{-}$. To calculate the surface tension of a solid, a minimum of three different reference liquids are required to determine these three variables. Ultrapure water, diiodomethane and ethylene glycol are commonly used as reference liquids, and their surface tensions obtained from the literature and are tabulated in Table 1 (Jańczuk and Białopiotrowicz 1990).

Table 1. Surface tension and surface tension components of reference materials at room temperature (Jańczuk and Białopiotrowicz 1990).

\begin{tabular}{c|ccccc} 
Material & $\gamma$ & $\gamma^{L W}$ & $\gamma^{A B}$ & $\gamma^{+}$ & $\gamma^{-}$ \\
\hline Water & 72.8 & 21.8 & 51.0 & 25.5 & 25.5 \\
Diiodomethane & 50.8 & 50.8 & 0 & 0 & 0 \\
Ethylene glycol & 48.0 & 29.0 & 19.0 & 1.9 & 47.0 \\
PTFE & 21.4 & 21.4 & 0 & 0 & 0
\end{tabular}

Note: Units are $\mathrm{mJ} / \mathrm{m}^{2}$. 


\subsection{Constant permeate flux crossflow fouling tests}

The constant permeate flux crossflow fouling apparatus used in this study has been described in detail elsewhere (He et al. 2016b, Miller et al. 2013). Crude oil-inwater emulsions were used to challenge a PVDF MF membrane in crossflow filtration tests. Membrane samples were 1.5 in $\times 3.5$ in $(3.81 \mathrm{~cm} \times 8.89 \mathrm{~cm})$. The effective filtration area was $19 \mathrm{~cm}^{2}$. Three membrane samples were tested simultaneously in each experiment.

Feed oil emulsion was pumped into the membrane cells at a constant volumetric flow rate of $2 \mathrm{~L} / \mathrm{min}$ and a crossflow velocity of $43 \mathrm{~cm} / \mathrm{s}$, which corresponded to a feed flow Reynolds number of 2500. A backpressure regulator was installed downstream of the membrane cells to maintain a constant feed pressure of $30 \mathrm{psig}(308 \mathrm{kPa})$. The permeate flow from each of the three membrane cells was controlled by a peristaltic pump operating in feedback control loop with a Corriolis ${ }^{\circledR}$ flow meter (Bronkhorst, The Netherlands) installed downstream of the peristaltic pump (Miller et al. 2013), so that the experiment could be operated at constant permeate flow rate (i.e., constant flux). A differential pressure transducer was installed on each membrane cell by connecting the high-pressure port of the transducer to the feed stream and the low-pressure port to the permeate stream. The transmembrane pressure, TMP, was calculated as described in the Supporting Information. The system was operated in a total recycle mode, so the retentate and permeate solutions were recycled back to the feed tank to maintain the feed concentration. Constant permeate flux crossflow fouling tests were conducted at two fluxes, 50 and $150 \mathrm{LMH}\left(\mathrm{Lm}^{-2} \mathrm{hr}^{-1}\right)$.

One modification of the crossflow fouling apparatus, relative to that described in the study of Miller et al. (2013), was the addition of a Microflow ${ }^{\circledR}$ inline particle analyzer 
(JM Canty, Buffalo, NY) (He et al. 2016b). This particle analyzer consists of a highspeed camera, an optical microscope, and a high intensity light source. A computer was connected to the particle analyzer to record videos of the feed emulsion during fouling experiments. The video was analyzed by the CANTY Vision Client software. Oil droplets were identified by their spherical shape. The particle analyzer can detect oil droplets larger than about $0.7 \mu \mathrm{m}$ in diameter.

\section{RESUltS AND DiscuSSION}

\subsection{Surface tension components}

The total surface tension of the crude oil, $\gamma_{c}$, was $22.5 \pm 0.2 \mathrm{~mJ} / \mathrm{m}^{2}$ based on a pendant drop measurement. The measured sessile drop contact angle, $\theta_{S}$, with respect to PTFE flat sheet was $24.2 \pm 3.6^{\circ}$. From Equation [11], the LW component of the crude oil surface tension, $\gamma_{c}^{L W}$, was calculated to be $21.7 \pm 1.7 \mathrm{~mJ} / \mathrm{m}^{2}$. The uncertainty in $\gamma_{c}^{L W}$ was calculated based on the propagation of uncertainties of the independent variables in Equation [13], $\theta_{S}$ and $\gamma_{l}$ (Bevington and Robinson 2002). The estimated $\gamma_{c}$ and $\gamma_{c}^{L W}$ values were equal to each other, within the uncertainty of the measurements. Pennsylvanian grade light crude oil is known to contain saturated $n$-alkanes, which are non-polar, and little sulfur and nitrogen content that may contribute to its polarity (Burruss and Ryder 2003). Therefore, it is reasonable to assume $\gamma_{c} \approx \gamma_{c}^{L W}$ for the Pennsylvanian grade light crude oil used in this study, indicating that the crude oil was likely to be non-polar.

Captive bubble contact angles, $\theta_{C}$, between the PVDF membrane and water, diiodomethane, and ethylene glycol were $20.7 \pm 1.4^{\circ}, 37.8 \pm 2.8^{\circ}$, and $19.9 \pm 1.5^{\circ}$, 
respectively. Using the measured $\theta_{C}$ and surface tensions of the reference liquids, the surface tension components of the PVDF membrane were calculated. Table 2 summarizes the surface tensions and surface tension components of the PVDF membrane, crude oil and ultrapure water. The presence of surfactant in the oil emulsions may have altered the surface energy of the dispersed phase (i.e., crude oil droplet) and the aqueous phase (i.e., water) (Tummons et al. 2016). Nonetheless, in the DLVO model calculations, surface properties of oil phase was assumed to be identical to those of crude oil, and surface properties of the aqueous environment was assumed to be identical to those of water, consistent with prior studies (Brant and Childress 2002).

Table 2. Surface tension components.

\begin{tabular}{c|c|ccccc} 
Material & Phase & $\gamma$ & $\gamma^{L W}$ & $\gamma^{A B}$ & $\gamma^{+}$ & $\gamma^{-}$ \\
\hline PVDF & $\mathrm{m}$ & 43.7 & 40.4 & 3.3 & 0.04 & 61.9 \\
Crude Oil & $\mathrm{c}$ & 22.5 & 21.7 & 0 & 0 & 0 \\
Water & 1 & 72.8 & 21.8 & 51.0 & 25.5 & 25.5
\end{tabular}

Note: Units are $\mathrm{mJ} / \mathrm{m}^{2}$.

\subsection{Fouling media conductivity and zeta potential}

Emulsion- 0 had a conductivity of approximately $1.1 \pm 0.2 \mu \mathrm{S} / \mathrm{cm}$ and a $\mathrm{pH}$ value of approximately 5.6, which were in the same range as those of $\mathrm{CO}_{2}$-equilibrated water (Francis 2008, Kamcev et al. 2015, Robinson and Stokes 2002). The apparent conductivity and $\mathrm{pH}$ value of Emulsion-0 was likely due to $\mathrm{CO}_{2}$ dissolution and speciation. The ionic strength of $\mathrm{CO}_{2}$-equilibrated water was calculated to be $2.24 \times 10^{-6}$ 
M, based on $\mathrm{HCO}_{3}{ }^{-}$and $\mathrm{H}^{+}$(i.e., the dominant ionic species at $\mathrm{pH}=5.6$ ) concentrations. This value, $2.24 \times 10^{-6} \mathrm{M}$, was taken to be the ionic strength of Emulsion-0 for later DLVO model calculations. Conductivities of Emulsion-3 and Emulsion-1 were 125 \pm 2 and $10,570 \pm 200 \mu \mathrm{S} / \mathrm{cm}$, respectively, which agreed with theoretical predictions. Detailed calculations of $\mathrm{CO}_{2}$-equilibrated water conductivity and ionic strength, as well as $\mathrm{NaCl}$ solution conductivity, are provided in the Supporting Information. Figure 2 presents foulant zeta potentials as a function of measured conductivity and estimated emulsion ionic strength. The surface charge (i.e., the absolute value of the zeta potential) decreased as salt concentration increased due to electrostatic screening (van Oss 2006). At low salt concentrations, the electrical double layer should be thick (cf., Equation [5]), which would extend the influence of the surface charge on an oil droplet further into solution than when the salt concentration was high. 


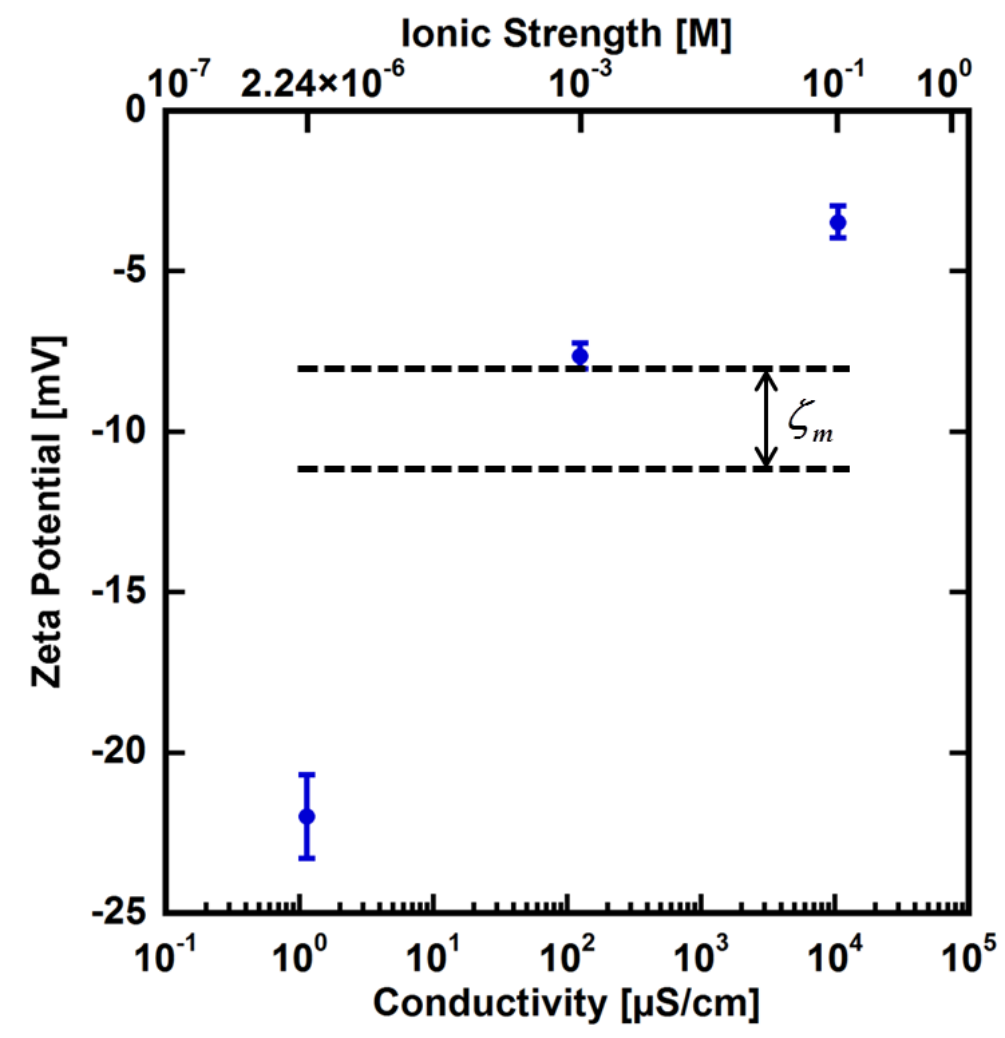

Figure 2. Influence of emulsion salt concentration on apparent $\zeta_{c}$. The blue dashed line is to guide the eye. The black dashed lines represent the range of membrane zeta potential, $\zeta_{m}$.

The zeta potential values were negative over the entire range of salt concentrations explored. The crude oil was non-polar, based on the surface energy analysis presented above. The Triton surfactant was non-ionic. The negative charge was attributed to preferential $\mathrm{OH}^{-}$adsorption at the oil-water interface. Uncharged hydrophobic surfaces, which are electrically neutral in air, often appear to have negative charges when immersed in polar solvents, such as water (Beattie 2006, Elimelech et al. 1994, Jordan and Taylor 1952). At the oil-water interface, hydroxide ions disassociate 
from protons and accumulate in the Stern layer. Preferential $\mathrm{OH}^{-}$adsorption to the interface leads to negative zeta potentials when hydrophobic materials are tested in electrokinetic measurements in aqueous environments. Similar effects have also been reported for solid hydrophobic polymers, air bubbles in water, and thin liquid films (Beattie 2006, Elimelech et al. 1994, Jordan and Taylor 1952, Marinova et al. 1996).

\subsection{Membrane zeta potential}

Because the oil emulsions had a $\mathrm{pH}$ value of 5.6, added salt concentrations of 0 , $10^{-3}$, and $10^{-1} \mathrm{M}$, and ionic strengths of $2.24 \times 10^{-6}, 10^{-3}$ and $10^{-1} \mathrm{M}$, membrane zeta potential should also be evaluated at such conditions. Water with no added salt has a conductivity value too low to be measured accurately. Therefore, the membrane zeta potential, which relies on accurate conductivity measurements, cannot be measured at zero salt concentration. Additionally, membrane zeta potential measurements cannot be performed in high concentration electrolyte solutions (e.g., $10^{-1} \mathrm{M} \mathrm{NaCl}$ ) due to limitations of the SurPASS electrokinetic analyzer (Coday et al. 2015). Therefore, $\zeta_{m}$ at $10^{-3} \mathrm{M}$ salt concentration was measured directly, and the Freundlich model was used to estimate $\zeta_{m}$ at 0 and $10^{-1} \mathrm{M}$ salt concentrations.

Typically, the zeta potential of polymeric membranes has been reported to remain fairly constant (i.e., less than $5 \mathrm{mV}$ difference) with respect to electrolyte concentration (Brant and Childress 2002, Childress and Elimelech 1996, Elimelech et al. 1994). The zeta potential of the PVDF membrane considered in this study was measured at five $\mathrm{NaCl}$ concentrations, $1,5,10,20$, and $50 \mathrm{mM}$, over a $\mathrm{pH}$ range of 4 to 9 . For clarity, Figure 3 only shows membrane zeta potential profiles at selected salt concentrations. Complete data set is presented in the Supporting Information. For all salt concentrations tested, the 
membrane zeta potential at $\mathrm{pH}=5.6$ varied by less than $3 \mathrm{mV}$, indicating salt concentration had little influence on membrane zeta potential at this $\mathrm{pH}$.

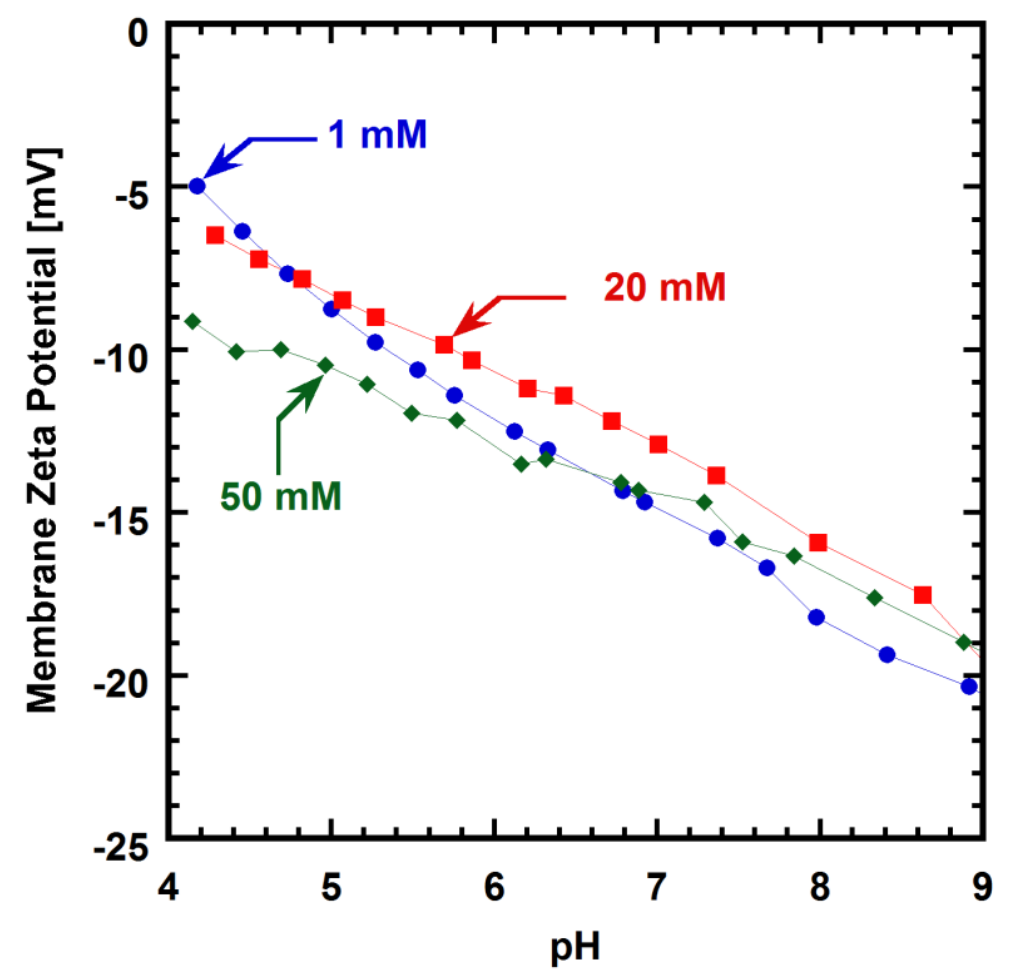

Figure 3. Influence of $\mathrm{NaCl}$ concentration on membrane zeta in a $\mathrm{pH}$ range of 4 to 9 . Three salt concentrations are $\bullet 1 \mathrm{mM}, \mathbf{a} 20 \mathrm{mM}$, and $\diamond 50 \mathrm{mM}$.

At $10^{-3} \mathrm{M}$ salt concentration, the measured membrane zeta potential was -10.9 $\mathrm{mV}$. Membrane zeta potentials at salt concentrations outside the experimental range were estimated using the Freundlich ion adsorption model (Han et al. 2011). The Freundlich ion adsorption model predicts that surface charge density has a power law dependence on ionic strength: (Ariza and Benavente 2001, Han et al. 2011, Peeters et al. 1999)

$$
\sigma=A I^{b}
$$


where $A$ and $b$ are fitting parameters. $I$ is the ionic strength, which numerically equals $\mathrm{NaCl}$ concentration, and $\sigma$ is the membrane surface charge density, which can be calculated as a function of membrane zeta potential, $\zeta_{m}$ : (Ariza and Benavente 2001, Han et al. 2011)

$$
\sigma=\frac{2 \varepsilon_{0} \varepsilon_{r} \kappa k T}{z e} \sinh \left(\frac{z e \zeta_{m}}{2 k T}\right)
$$

Membrane surface charge densities at a $\mathrm{pH}$ of 5.6 were calculated and plotted with respect to $I$. The Freundlich model was fit to these data in Figure 4. Goodness of fit, $\mathrm{R}^{2}$, was 0.96 , suggesting the model is applicable to the PVDF membrane. Membrane surface charge density can be extrapolated using the fitted power law relationship. The estimated zeta potentials based on the surface charge density, $\zeta_{m, c=0}=-8.8 \mathrm{mV}$ and $\zeta_{m, c=10^{-1} M}=-10.9 \mathrm{mV}$, were consistent with the measured zeta potential values presented in Figure 3. The measured membrane zeta potential at $10^{-3} \mathrm{M}$ added salt concentration and estimated membrane zeta potentials at 0 and $10^{-1} \mathrm{M}$ added salt concentrations were used in later DLVO calculations. 


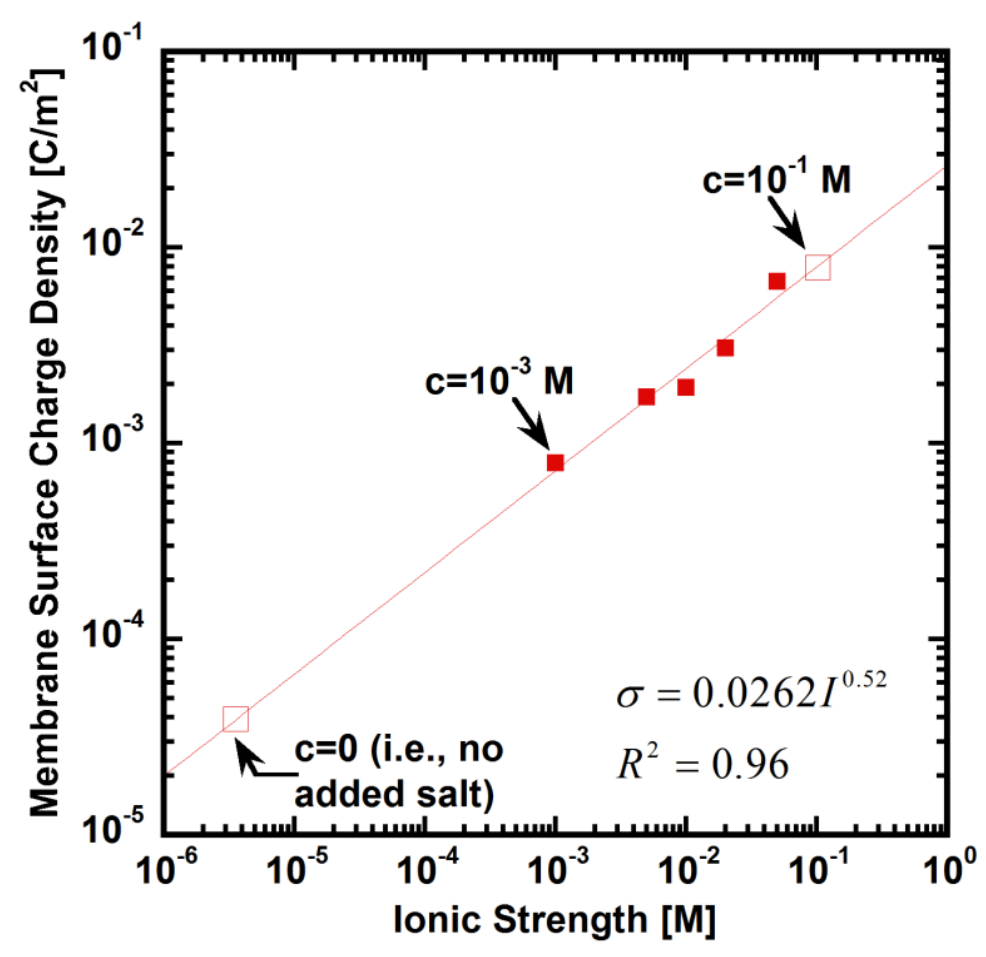

Figure 4. Influence of ionic strength, $I$, on calculated membrane surface charge density, $\sigma$, at $\mathrm{pH}=5.6$. Closed symbols $(\boldsymbol{\square})$ are calculated surface charge density using Equation [15]. Open symbols ( $\square$ ) are estimated values based on the Freundlich model. $\mathrm{R}^{2}$ is the goodness of fit. The values of ionic strength of the emulsions considered in this study are shown, along with their added salt concentrations, $\mathrm{c}$.

\subsection{Oil droplet size and size distribution}

Oil droplet size was monitored inline during constant permeate flux crossflow fouling experiments. Figure 5 presents oil droplet size distributions based on the cumulative number of droplets analyzed during 15 minutes of crossflow fouling experiments. Although not shown in the figure, most of the oil droplets were smaller than $10 \mu \mathrm{m}$ in diameter, and less than $1 \%$ were larger than $10 \mu \mathrm{m}$. The oil droplet distribution was unchanged throughout the experiment, indicating that oil emulsions were 
rather stable at least for the duration of the experiment. The average oil droplet diameter, $\bar{d}$, was 3.2 to $3.4 \mu \mathrm{m}$, and the standard deviation, $\sigma$, was 1.5 to $1.6 \mu \mathrm{m}$. The red line is a log-normal distribution fitted using the MATLAB ${ }^{\circledR}$ distribution toolbox (MathWorks, Natick, MA) (Fieber et al. 2011, Limpert et al. 2001). The CANTY inline particle analyzer is limited in detecting oil droplets smaller than $0.7 \mu \mathrm{m}$. Therefore, smaller oil droplets and soluble organics, which might be present in the oil emulsions, were not accounted for in the size distribution. Based on the log-normal fitting, less than $1 \%$ of oil droplets were expected to be smaller than $0.7 \mu \mathrm{m}$. 

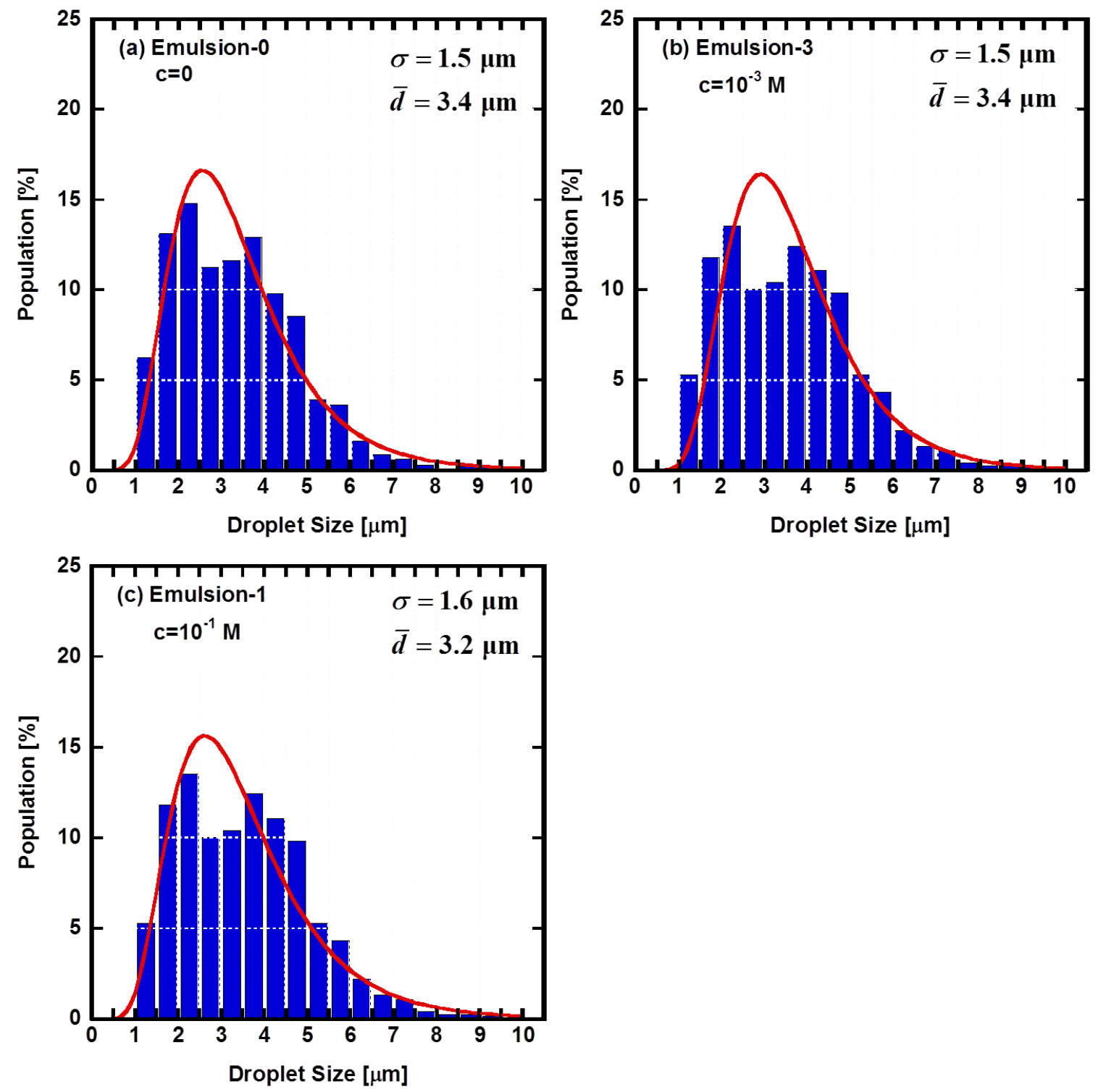

Figure 5. Emulsified oil droplet size distribution of the three crude oil-in-water emulsions. The distribution was based on the cumulative number of droplets The $\mathrm{c}$ values are the added salt concentrations. The blue bars are averages of droplet distributions captured over 15 minutes. The red line is the fitted lognormal distribution. The oil droplets had an average size of $\bar{d}$ and a standard deviation of $\sigma$. 


\subsection{DLVO model calculations}

Figure 6 shows a schematic of several forces acting on an oil droplet near a membrane surface during microfiltration (Bacchin et al. 2002, Harmant and Aimar 1998, Jiao and Sharma 1994, Kim and Hoek 2007, Tang et al. 2009, Vigneswaran and Kwon 2014). The balance between membrane-oil droplet surface interactions, drag force exerted by convective permeate flow, and shear force due to crossflow determines whether an oil droplet deposits on a membrane surface or not. Many phenomena are not represented in Figure 6, such as the hydrophobic-hydrophobic interactions, inertia lift within the boundary layer, interactions between oil droplets within close proximity. A force balance on a single oil droplet would have been extremely difficult and inaccurate without accounting for these interactions.

In this study, we focused on estimating membrane-oil droplet and oil layer-oil droplet surface interactions. Membrane-oil droplet surface interactions influence initial foulant deposition (Brant and Childress 2002). During filtration, as oil droplets are brought to the membrane surface, some may deposit on the membrane surface. With sufficient oil droplet deposition and coalescence, a layer of predominantly oil can develop on the membrane surface, as observed in previous studies (He et al. 2016b, Tummons et al. 2016). In this case, oil layer-oil droplet surface interactions replace membrane-oil droplet surface interactions (Brant and Childress 2002, Li and Elimelech 2006). As discussed in detail later, the membrane-oil droplet and oil layer-oil droplet surface interactions in this study are often repulsive. Therefore, these surface interactions act to mitigate fouling. 


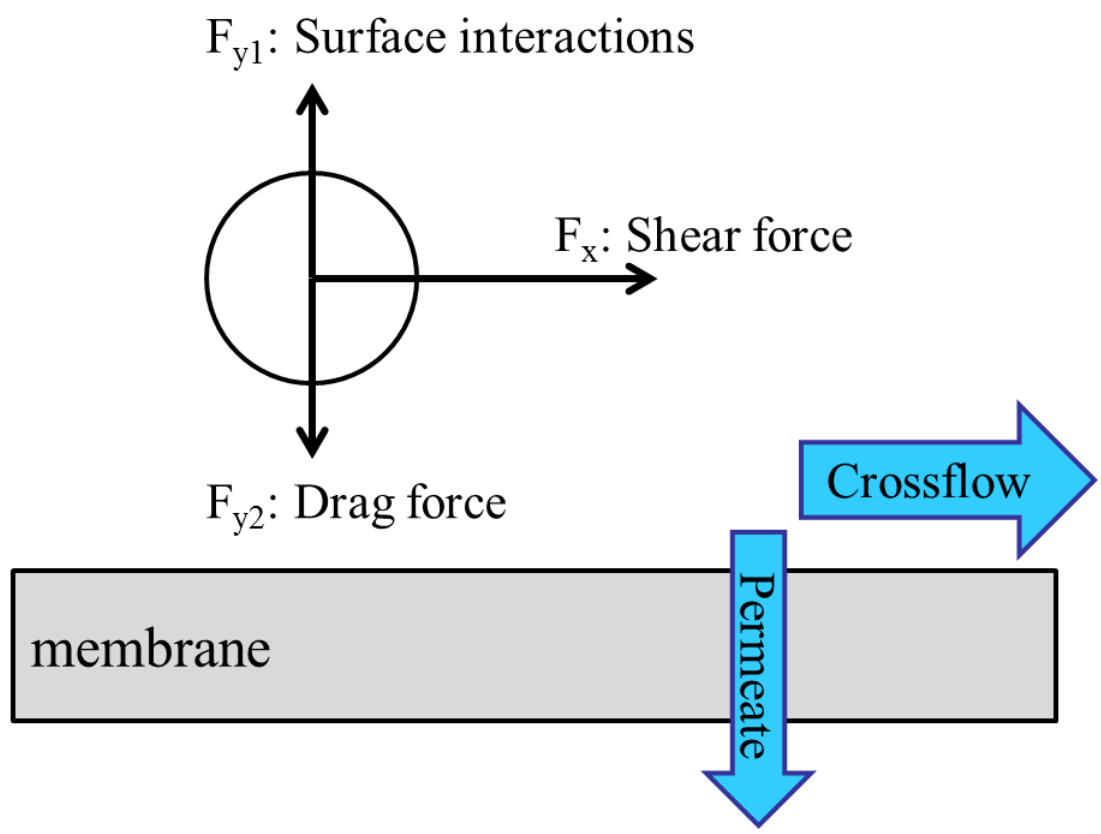

Figure 6. An illustration of forces experienced by an oil droplet near a membrane surface (Bacchin et al. 2002, Harmant and Aimar 1998, Jiao and Sharma 1994, Kim and Hoek 2007, Tang et al. 2009, Vigneswaran and Kwon 2014). The $\mathrm{x}$-axis is parallel to the membrane surface. The $\mathrm{y}$-axis is perpendicular to the membrane surface. The shear force due to crossflow, $\mathrm{F}_{\mathrm{x}}$, acts in the $\mathrm{x}-$ direction, and the surface interactions, $\mathrm{F}_{\mathrm{y} 1}$, and drag force, $\mathrm{F}_{\mathrm{y} 2}$, act in the $\mathrm{y}$ direction.

The LW interaction energy was calculated using the surface tension values recorded in Table 2. Membrane and crude oil zeta potentials were used in EL interaction energy calculations. Similar DLVO and XDLVO model calculations have been performed on systems involving membranes interacting with solid particulates or colloidal matter (Aimar and Bacchin 2010, Bacchin et al. 1995, Bacchin et al. 2002, Brant and Childress 2002, Hoek et al. 2003, Muthu et al. 2014). The separation distance considered ranged from $10 \mathrm{~nm}$ to $1 \mu \mathrm{m}$, a relevant range for these interactions that is also comparable to that used in previous studies (Aimar and Bacchin 2010, Bacchin et al. 
1995, Bacchin et al. 2002, Brant and Childress 2002, Hoek et al. 2003, Muthu et al. 2014). Alternatively, at closer separation distances, the incoming oil droplet and the membrane can be treated as parallel flat plates, similarly to the approach employed by Vasan et al. (Vasan et al. 2006).

Membrane-oil droplet interaction energies are presented in Figure 7. Membraneoil droplet LW, EL and total DLVO interaction energies are shown in Figure 7(a), (b), and (c), respectively. Negative interaction energies indicate attractive interactions, while positive interaction energies indicate repulsive interactions. The membrane-oil droplet LW surface interaction was repulsive. Because the LW interaction energy is a function of membrane and crude oil surface tensions (cf., Equation [10]), it does not vary with salt concentration. The EL surface interaction was repulsive as well. The EL interaction energy varied with salt concentration (i.e., ionic strength), because its independent variables, $\kappa$ and $\zeta_{c}$, are functions of emulsion ionic strength (cf., Equations [12]). The EL surface interactions extended further into the surrounding medium at lower salt concentration, as a result of a thicker electrical double layer.

At all salt concentrations considered, the EL interaction energy was orders of magnitudes greater than the LW interaction energy. Therefore, the EL interaction energy was dominant in membrane-oil droplet surface interactions, consistent with previous findings (Bacchin et al. 2002, Brant and Childress 2002). The total DLVO interaction energy, which is the sum of the LW and EL interactions, was repulsive at all salt concentrations considered. A more repulsive membrane-oil droplet surface interaction could lead to slower initial rates of fouling. 

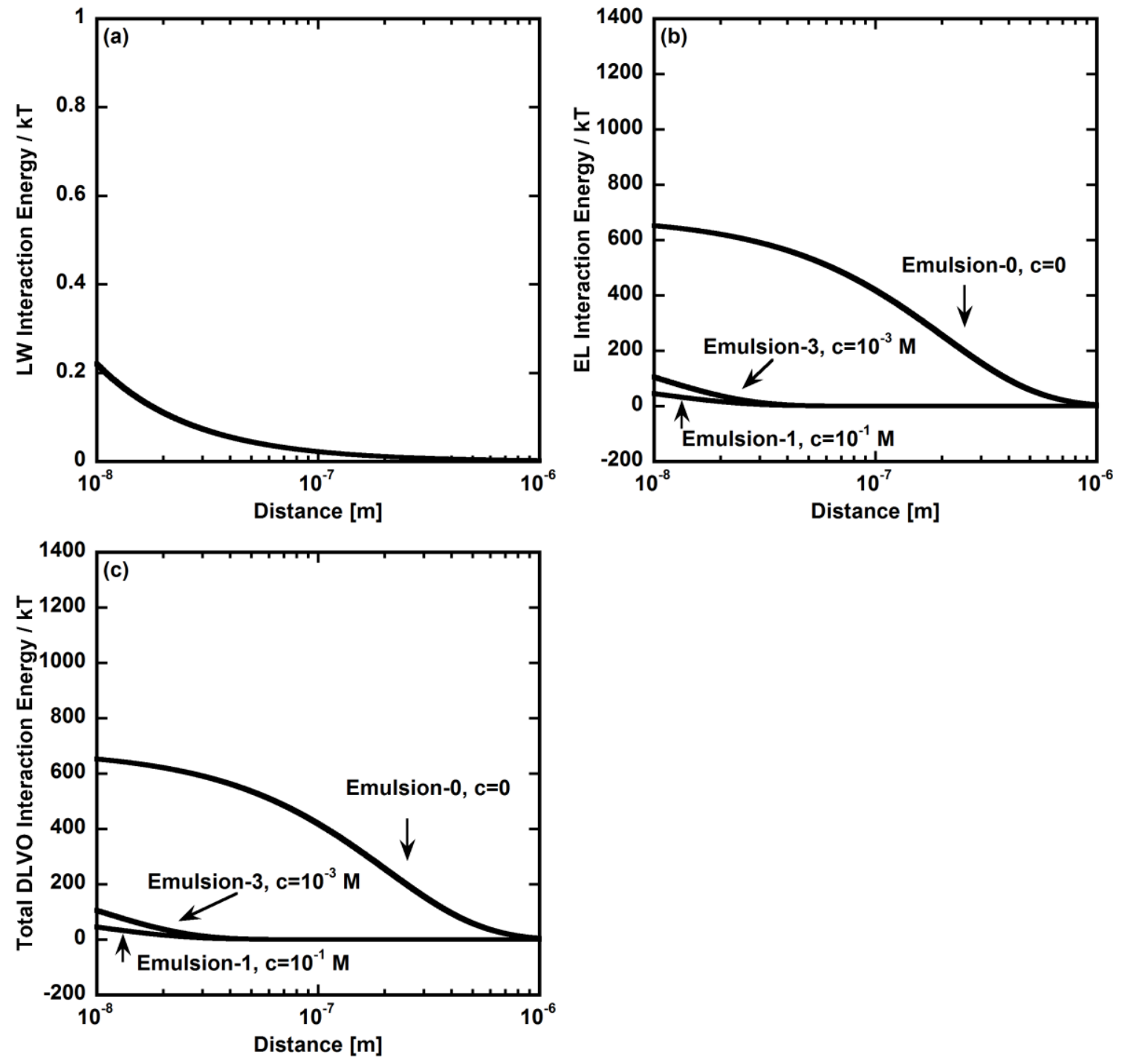

Figure 7. Influence of salt concentration on membrane-oil droplet: (a) LW interaction energy, (b) EL interaction energy and (c) total DLVO interaction energy. The $\mathrm{c}$ values are added salt concentrations. 
The oil layer-oil droplet surface interactions were also calculated to simulate a membrane surface completely covered by a layer of oil (Brant and Childress 2002, Ding et al. 2013, He et al. 2016b, Tummons et al. 2016). In this case, the sphere-plate system was also used. The membrane surface properties were replaced with those of the crude oil to represent the oil layer (i.e., $\gamma_{m}^{L W}=\gamma_{c}^{L W}$ in calculating $\Delta G^{L W}$ using Equation [9]) (Brant and Childress 2002, Ding et al. 2013). Figure 8 presents the LW, EL and total DLVO interaction energies. The oil layer-oil droplet LW surface interaction was slightly attractive because the surface properties of the oil droplet and the oil layer were taken to be identical to one another. The EL repulsion decreased with increasing salt concentration. At lower salt concentrations (i.e., Emulsion-0 and Emulsion-3), the EL interaction energy was stronger than the LW interaction energy, especially at shorter separation distances. Therefore, the EL interaction was dominant over the LW interaction, resulting in a repulsive total DLVO interaction energy. At high salt concentrations, EL surface interactions were screened. The total DLVO energy was slightly attractive for Emulsion-1 due to the attractive LW interaction. 

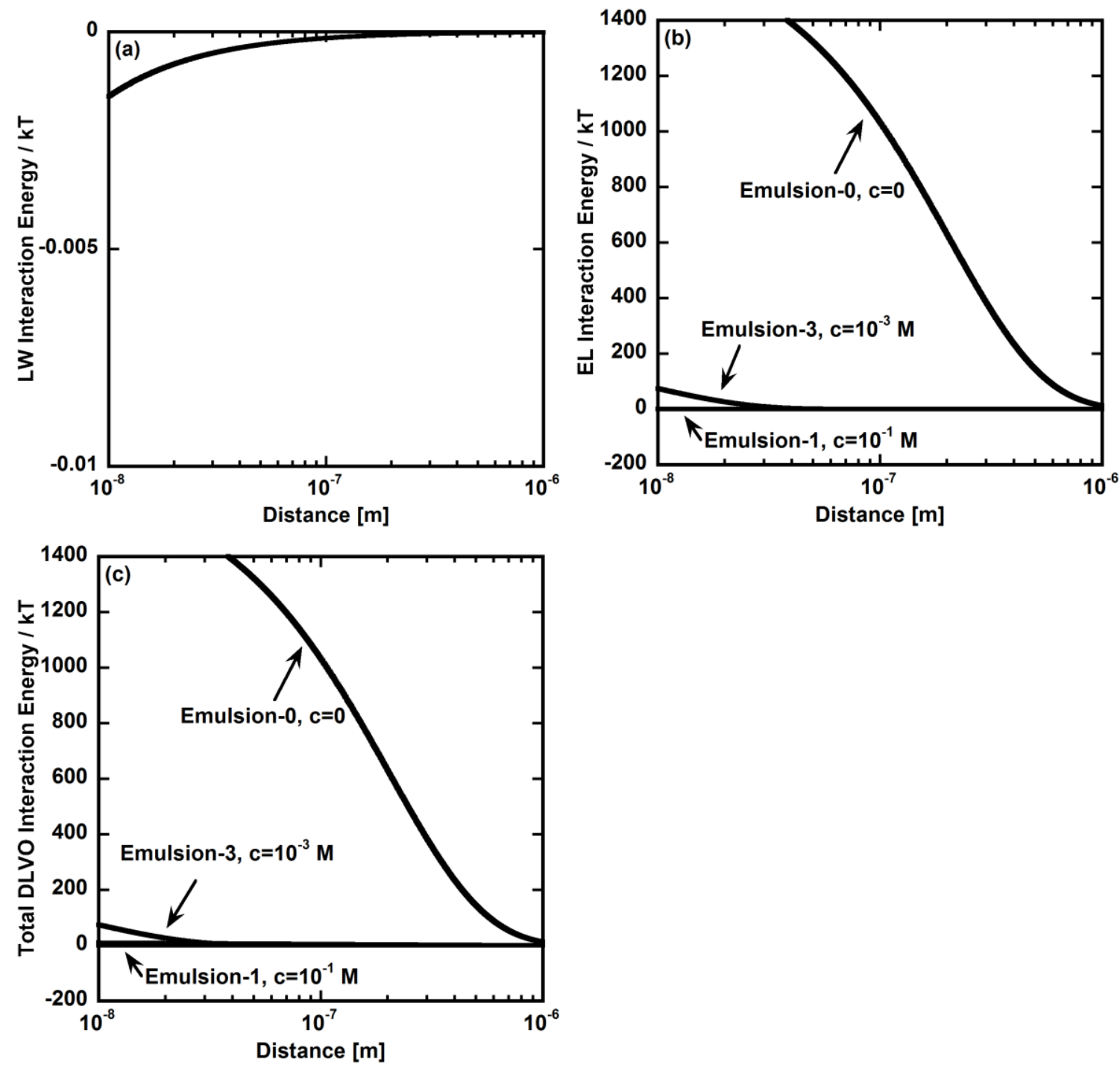

Figure 8. Influence of salt concentration on oil layer-oil droplet: (a) LW interaction energy, (b) EL interaction energy and (c) total DLVO interaction energy. The $\mathrm{c}$ values are added salt concentrations.

The EL surface interaction was dominant in both membrane-oil droplet and oil layer-oil droplet DLVO surface interactions (cf., Figures 7 and 8). As shown in Equation [12], the EL interaction energy depends on the surface charge of the two approaching surfaces. Emulsion salt concentration showed a strong influence on oil droplet surface 
charge, so it strongly influenced the EL interaction energy. The zeta potential of Emulsion-0 was more negative than that of the PVDF membrane surface (cf., Figure 2). Therefore, the oil layer-oil droplet EL and DLVO surface interactions were more repulsive than membrane-oil droplet interactions, as shown in Figure 7 and Figure 8. For Emulsion-3 and Emulsion-1, the oil layer-oil droplet EL and DLVO surface interactions were less repulsive than those of membrane-oil droplet, because the oil layer was less negatively charged than the PVDF membrane.

If the total DLVO interaction energy values presented in Figures 7 and 8 are important to fouling, the fouling propensity of the three crude oil-in-water emulsions should relate directly to their salt concentration and surface charge. The fouling propensity should increase with increasing salt concentration because the calculated DLVO energy was less repulsive at higher salt concentration. The EL interaction energy dominance suggests the use of negatively charged membranes may result in better fouling resistance.

\subsection{Membrane fouling}

Constant permeate flux crossflow fouling experiments were performed at 150 LMH $\left(\mathrm{Lm}^{-2} \mathrm{hr}^{-1}\right)$, to compare the fouling behavior of the three crude oil-in-water emulsions. Because the permeate flux was held constant, the transmembrane pressure, which is the driving force for filtration, increased as fouling increased the mass transfer resistance. Higher TMP values indicate more extensive fouling. The TMP profiles with

respect to cumulative permeate volume per unit area, $\frac{V}{A}$, are shown in Figure 9. The increase in TMP was more significant at higher salt concentration than at lower salt concentration, suggesting more severe fouling at higher salt concentration, consistent 
with results from other such studies (Li et al. 2010, Singh and Song 2005, Vigneswaran and Kwon 2014). A similar correspondence between calculated surface interactions with fouling propensity was also observed in previous studies (Brant and Childress 2002, Ding et al. 2013). Brant and Childress (2002) applied the DLVO and XDLVO models on a combination of three membranes and three types of colloidal foulants. The observed fouling propensity qualitatively correlated with expectations from DLVO and XDLVO models. Ding et al. (2013) observed decreasing permeate flux, more attractive membraneBSA interaction, as well as more attractive BSA layer-incoming BSA interaction, with increasing ionic strength. 


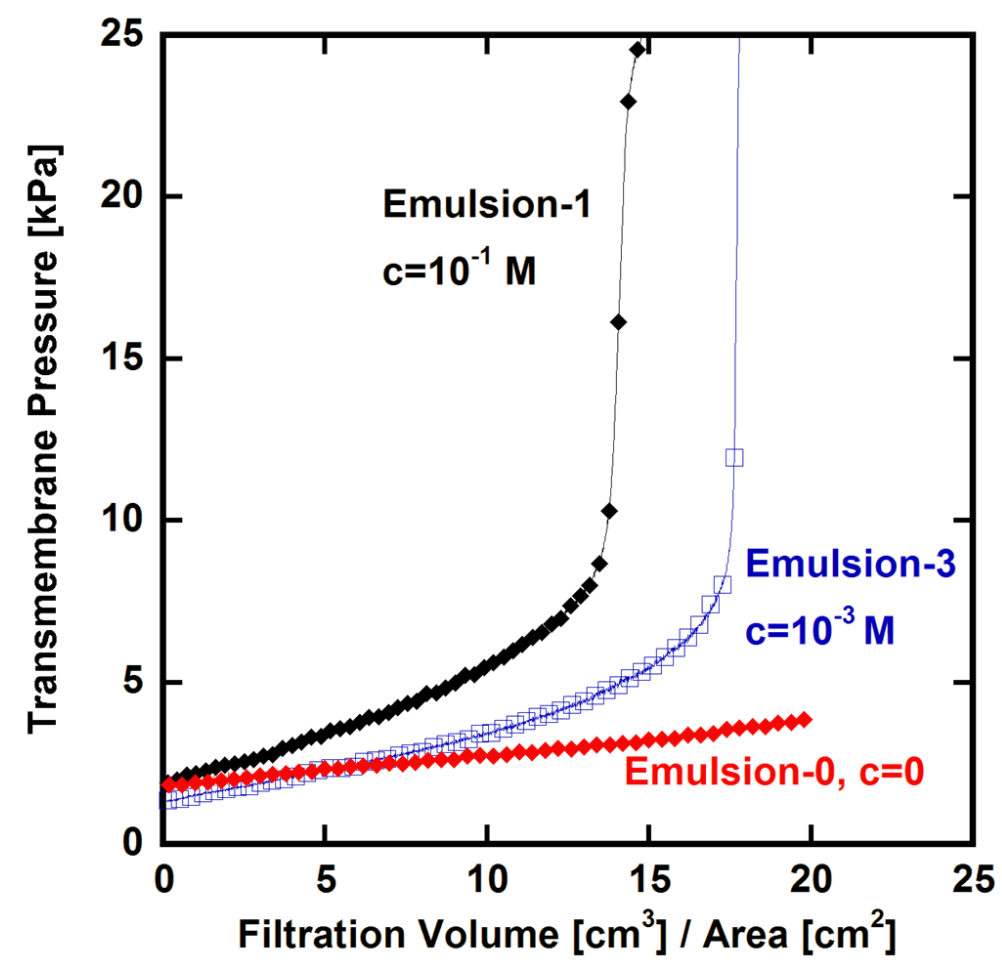

Figure 9. Effect of feed salt concentration on PVDF MF membrane fouling behavior by crude oil-in-water emulsions in constant flux fouling experiments operated at $-150 \mathrm{LMH}$. Feed flow rate $=2 \mathrm{~L} / \mathrm{min}$, crossflow velocity $=43$ $\mathrm{cm} / \mathrm{s}$, feed pressure $=30 \mathrm{psig}(308 \mathrm{kPa})$. The $\mathrm{c}$ values are added salt concentrations.

Based on a previous study, the threshold flux of Emulsion-0 was $88 \mathrm{LMH}$ (He et al. 2016b). In constant flux fouling tests, Emulsion-3 and Emulsion-1 showed an upwards curvature in their TMP profile, whereas the TMP profile of the Emulsion- 0 was fairly linear at $\frac{V}{A} \leq 20 \mathrm{~cm}$. This upwards curvature is often described as the "self-accelerating" phase of membrane fouling (He et al. 2016a, Liu and Kim 2008, Miller et al. 2014a, Miller et al. 2014b). In a constant permeate flux experiment, the pore size decreases and 
local flux increases as a result of fouling, such that the TMP increases slowly at the beginning of a fouling experiment and then exhibits a marked and rapid increase (Fane 2007, Ho and Zydney 2002, Miller et al. 2014a, Miller et al. 2014b). In our case, the selfaccelerating phenomena can also be correlated with membrane-oil droplet and oil layeroil droplet interactions. The shape of TMP profile and organic rejections for the PVDF membrane are investigated in detail elsewhere (He et al. 2016a). For Emulsion-1 and Emulsion-3, the membrane-oil droplet repulsion was stronger than the oil layer-oil droplet repulsion. During a fouling test, an oil droplet first interacts with a clean membrane surface. Once the membrane surface is covered by oil, the surface interactions shift to the interaction between an oil droplet and the oil layer, which is weaker (cf., Figure 7 and Figure 8). The repulsion decreases as oil coverage on the membrane surface grows. As a result, the rate of fouling increased with increasing oil coverage, which can also contribute to the self-accelerated fouling process. As anticipated by the DLVO model results shown in Figure 7 and Figure 8, the fouling propensity increased with increasing emulsion salt concentration. Increasing salt concentration increased fouling propensity and likely reduced the threshold flux.

\section{Conclusions}

In this study, the effects of salt concentration and oil droplet surface charge on membrane fouling were investigated. Crude oil-in-water emulsions of various salt concentrations were formulated. Emulsion zeta potential decreased with increasing salt concentration due to electrostatic screening. Surface properties of a PVDF MF membrane, including zeta potential and surface tensions, were characterized. The DLVO model was used to calculate membrane-oil droplet and oil layer-oil droplet surface 
interactions. The calculated interaction energies showed that EL surface interactions were often dominant over LW surface interactions, resulting in a net repulsive interaction. The DLVO model predicted emulsion fouling propensity to increase with increasing salt concentration. The PVDF MF membrane was challenged with crude oil-in-water emulsions in constant permeate flux crossflow fouling tests. The extent of fouling was consistent with the DLVO model predicted fouling propensity.

\section{ACKNOWLEDGMENTS}

The authors gratefully acknowledge financial support from Pall Corporation, James Fair Process Science and Technology Center at The University of Texas at Austin, the National Science Foundation (NSF) Center for Layered Polymeric Systems (DMR0423914), and NSF Grant CBET 1160069. We would also like to thank American Refining Group for providing the crude oil.

\section{REFERENCES}

Adamczyk, Z. and Warszyński, P. (1996) Role of electrostatic interactions in particle adsorption. Advances in Colloid and Interface Science 63, 41-149.

Aimar, P. and Bacchin, P. (2010) Slow colloidal aggregation and membrane fouling. Journal of Membrane Science 360(1-2), 70-76.

Arashiro, E.Y. and Demarquette, N.R. (1999) Use of the pendant drop method to measure interfacial tension between molten polymers. Materials Research 2, 23-32.

Ariza, M.J. and Benavente, J. (2001) Streaming potential along the surface of polysulfone membranes: A comparative study between two different experimental systems and determination of electrokinetic and adsorption parameters. Journal of Membrane Science 190(1), 119-132.

Bacchin, P., Aimar, P. and Sanchez, V. (1995) Model for colloidal fouling of membranes. AIChE Journal 41(2), 368-376. 
Bacchin, P., Si-Hassen, D., Starov, V., Clifton, M.J. and Aimar, P. (2002) A unifying model for concentration polarization, gel-layer formation and particle deposition in cross-flow membrane filtration of colloidal suspensions. Chemical Engineering Science 57(1), 77-91.

Baker, R.W. (2004) Membrane Technology and Applications, John Wiley \& Sons, West Sussex, England.

Bard, A.J. and Faulkner, L.R. (2001) Electrochemical Methods: Fundamentals and Applications, John Wiley \& Sons, New York, NY.

Beattie, J.K. (2006) The intrinsic charge on hydrophobic microfluidic substrates. Lab on a Chip 6(11), 1409-1411.

Bevington, P. and Robinson, D.K. (2002) Data Reduction and Error Analysis for the Physical Sciences, McGraw-Hill Education, New York.

Binks, B.P., Murakami, R., Armes, S.P. and Fujii, S. (2006) Effects of pH and salt concentration on oil-in-water emulsions stabilized solely by nanocomposite microgel particles. Langmuir 22(5), 2050-2057.

Brant, J.A. and Childress, A.E. (2002) Assessing short-range membrane-colloid interactions using surface energetics. Journal of Membrane Science 203(1-2), 257-273.

Burruss, R.C. and Ryder, R.T., Composition of crude oil and natural gas produced from 14 wells in the Lower Silurian 'Clinton' Sandstone and Medina Group, north Ohio and northwestern Pennsylvania. U.S. Geological Survey, 2003, Open-File Report 03-409.

http://pubs.usgs.gov/of/2003/of03-409/

Busscher, H.J. and Arends, J. (1981) Determination of the surface forces $\gamma_{\mathrm{s}}{ }^{\mathrm{d}}$ and $\gamma_{\mathrm{s}}{ }^{\mathrm{P}}$ from contact angle measurements on polymers and dental enamel. Journal of Colloid and Interface Science 81(1), 75-79.

Childress, A.E. and Elimelech, M. (1996) Effect of solution chemistry on the surface charge of polymeric reverse osmosis and nanofiltration membranes. Journal of Membrane Science 119(2), 253-268.

Coday, B.D., Luxbacher, T., Childress, A.E., Almaraz, N., Xu, P. and Cath, T.Y. (2015) Indirect determination of zeta potential at high ionic strength: Specific application to semipermeable polymeric membranes. Journal of Membrane Science 478, 5864.

Delgado, A.V., González-Caballero, F., Hunter, R.J., Koopal, L.K. and Lyklema, J. (2007) Measurement and interpretation of electrokinetic phenomena. Journal of Colloid and Interface Science 309(2), 194-224. 
Ding, Y., Tian, Y., Li, Z., Wang, H. and Chen, L. (2013) Microfiltration (MF) membrane fouling potential evaluation of protein with different ion strengths and divalent cations based on extended DLVO theory. Desalination 331(0), 62-68.

Elimelech, M., Chen, W.H. and Waypa, J.J. (1994) Measuring the zeta (electrokinetic) potential of reverse osmosis membranes by a streaming potential analyzer. Desalination 95(3), 269-286.

Elmaleh, S. and Ghaffor, N. (1996) Cross-flow ultrafiltration of hydrocarbon and biological solid mixed suspensions. Journal of Membrane Science 118(1), 111120.

Fane, A.G. (2007) Sustainability and membrane processing of wastewater for reuse. Desalination 202(1-3), 53-58.

Fane, A.G., Fell, C.J.D. and Suki, A. (1983) The effect of pH and ionic environment on the ultrafiltration of protein solutions with retentive membranes. Journal of Membrane Science 16, 195-210.

Fieber, W., Hafner, V. and Normand, V. (2011) Oil droplet size determination in complex flavor delivery systems by diffusion NMR spectroscopy. Journal of Colloid and Interface Science 356(2), 422-428.

Fievet, P., Szymczyk, A., Labbez, C., Aoubiza, B., Simon, C., Foissy, A. and Pagetti, J. (2001) Determining the zeta potential of porous membranes using electrolyte conductivity inside pores. Journal of Colloid and Interface Science 235(2), 383390.

Francis, M.J. (2008) Effect of degassing on the electrical conductivity of pure water and potassium chloride solutions. The Journal of Physical Chemistry C 112(37), 14563-14569.

Geise, G.M., Lee, H.-S., Miller, D.J., Freeman, B.D., McGrath, J.E. and Paul, D.R. (2010) Water purification by membranes: The role of polymer science. Journal of Polymer Science Part B: Polymer Physics 48(15), 1685-1718.

Gregory, J. (1975) Interaction of unequal double layers at constant charge. Journal of Colloid and Interface Science 51(1), 44-51.

Han, M.J., Baroña, G.N.B. and Jung, B. (2011) Effect of surface charge on hydrophilically modified poly(vinylidene fluoride) membrane for microfiltration. Desalination 270(1-3), 76-83.

Hansen, F.K. and Rødsrud, G. (1991) Surface tension by pendant drop: I. A fast standard instrument using computer image analysis. Journal of Colloid and Interface Science 141(1), 1-9. 
Harmant, P. and Aimar, P. (1998) Coagulation of colloids in a boundary layer during cross-flow filtration. Colloids and Surfaces A: Physicochemical and Engineering Aspects 138(2-3), 217-230.

He, Z., Miller, D.J., Kasemset, S., Paul, D.R. and Freeman, B.D. (2016a) The effect of permeate flux on membrane fouling during microfiltration of oily water. Journal of Membrane Science.

He, Z., Miller, D.J., Kasemset, S., Wang, L., Paul, D.R. and Freeman, B.D. (2016b) Fouling propensity of a poly(vinylidene fluoride) microfiltration membrane to several model oil/water emulsions. Journal of Membrane Science DOI: 10.1016/j.memsci.2016.04.018.

Hesampour, M., Krzyzaniak, A. and Nyström, M. (2008) The influence of different factors on the stability and ultrafiltration of emulsified oil in water. Journal of Membrane Science 325(1), 199-208.

Ho, C.-C. and Zydney, A.L. (2002) Transmembrane pressure profiles during constant flux microfiltration of bovine serum albumin. Journal of Membrane Science 209(2), 363-377.

Hoek, E.M.V., Bhattacharjee, S. and Elimelech, M. (2003) Effect of membrane surface roughness on colloid-membrane DLVO interactions. Langmuir 19(11), 48364847.

Howe, K.J. and Clark, M.M. (2002) Fouling of microfiltration and ultrafiltration membranes by natural waters. Environmental Science \& Technology 36(16), 3571-3576.

Jańczuk, B. and Białopiotrowicz, T. (1990) The total surface free energy and the contact angle in the case of low energetic solids. Journal of Colloid and Interface Science 140(2), 362-372.

Janknecht, P., Lopes, A.D. and Mendes, A.M. (2004) Removal of industrial cutting oil from oil emulsions by polymeric ultra- and microfiltration membranes. Environmental Science \& Technology 38(18), 4878-4883.

Jiao, D. and Sharma, M.M. (1994) Mechanism of cake buildup in crossflow filtration of colloidal suspensions. Journal of Colloid and Interface Science 162(2), 454-462.

Jordan, D.O. and Taylor, A.J. (1952) The electrophoretic mobilities of hydrocarbon droplets in water and dilute solutions of ethyl alcohol. Transactions of the Faraday Society 48(0), 346-355.

Kamcev, J., Jang, E.-S., Yan, N., Paul, D.R. and Freeman, B.D. (2015) Effect of ambient carbon dioxide on salt permeability and sorption measurements in ion-exchange membranes. Journal of Membrane Science 479, 55-66. 
Kim, S. and Hoek, E.M.V. (2007) Interactions controlling biopolymer fouling of reverse osmosis membranes. Desalination 202(1-3), 333-342.

Lee, S. and Elimelech, M. (2006) Relating organic fouling of reverse osmosis membranes to intermolecular adhesion forces. Environmental Science \& Technology 40(3), 980-987.

Li, Q. and Elimelech, M. (2006) Synergistic effects in combined fouling of a loose nanofiltration membrane by colloidal materials and natural organic matter. Journal of Membrane Science 278(1-2), 72-82.

Li, S., Heijman, S.G.J., Verberk, J.Q.J.C. and van Dijk, J.C. (2010) Influence of Ca and $\mathrm{Na}$ ions in backwash water on ultrafiltration fouling control. Desalination 250(2), 861-864.

Limpert, E., Stahel, W.A. and Abbt, M. (2001) Log-normal distributions across the Sciences: Keys and clues. BioScience 51(5), 341-352.

Lin, S. and Wiesner, M.R. (2010) Exact analytical expressions for the potential of electrical double layer interactions for a sphere-plate system. Langmuir 26(22), 16638-16641.

Liu, Q.-F. and Kim, S.-H. (2008) Evaluation of membrane fouling models based on bench-scale experiments: A comparison between constant flowrate blocking laws and artificial neural network (ANNS) model. Journal of Membrane Science 310(1-2), 393-401.

Marinova, K.G., Alargova, R.G., Denkov, N.D., Velev, O.D., Petsev, D.N., Ivanov, I.B. and Borwankar, R.P. (1996) Charging of oil-water interfaces due to spontaneous adsorption of hydroxyl ions. Langmuir 12(8), 2045-2051.

Miller, D.J., Kasemset, S., Paul, D.R. and Freeman, B.D. (2014a) Comparison of membrane fouling at constant flux and constant transmembrane pressure conditions. Journal of Membrane Science 454(0), 505-515.

Miller, D.J., Kasemset, S., Wang, L., Paul, D.R. and Freeman, B.D. (2014b) Constant flux crossflow filtration evaluation of surface-modified fouling-resistant membranes. Journal of Membrane Science 452(0), 171-183.

Miller, D.J., Paul, D.R. and Freeman, B.D. (2013) A crossflow filtration system for constant permeate flux membrane fouling characterization. Review of Scientific Instruments 84(3), 035003-035011.

Muthu, S., Childress, A. and Brant, J. (2014) Propagation-of-uncertainty from contact angle and streaming potential measurements to XDLVO model assessments of membrane-colloid interactions. Journal of Colloid and Interface Science 428, 191-198. 
Peeters, J.M.M., Mulder, M.H.V. and Strathmann, H. (1999) Streaming potential measurements as a characterization method for nanofiltration membranes. Colloids and Surfaces A: Physicochemical and Engineering Aspects 150(1-3), 247-259.

Petosa, A.R., Jaisi, D.P., Quevedo, I.R., Elimelech, M. and Tufenkji, N. (2010) Aggregation and deposition of engineered nanomaterials in aquatic environments: Role of physicochemical interactions. Environmental Science \& Technology 44(17), 6532-6549.

Poortinga, A.T., Bos, R., Norde, W. and Busscher, H.J. (2002) Electric double layer interactions in bacterial adhesion to surfaces. Surface Science Reports 47(1), 132.

Probstein, R.F. (1994) Physicochemical Hydrodynamics: An Introduction, John Wiley \& Sons, New York.

Ramesh Babu, S. (1986) An absolute method for the determination of surface tension of liquids using pendent drop profiles. Bulletin of Materials Science 8(2), 217-224.

Robinson, R.A. and Stokes, R.H. (2002) Electrolyte Solutions, Butterworth \& Co. (Publishers) Ltd., London, UK.

Saad, S.M.I., Policova, Z. and Neumann, A.W. (2011) Design and accuracy of pendant drop methods for surface tension measurement. Colloids and Surfaces A: Physicochemical and Engineering Aspects 384(1-3), 442-452.

Singh, G. and Song, L. (2005) Quantifying the effect of ionic strength on colloidal fouling potential in membrane filtration. Journal of Colloid and Interface Science 284(2), 630-638.

Stauffer, C.E. (1965) The Measurement of surface tension by the pendant drop technique. The Journal of Physical Chemistry 69(6), 1933-1938.

Tang, C.Y., Kwon, Y.-N. and Leckie, J.O. (2009) The role of foulant-foulant electrostatic interaction on limiting flux for RO and NF membranes during humic acid fouling - Theoretical basis, experimental evidence, and AFM interaction force measurement. Journal of Membrane Science 326(2), 526-532.

Tummons, E.N., Tarabara, V.V., Chew, J.W. and Fane, A.G. (2016) Behavior of oil droplets at the membrane surface during crossflow microfiltration of oil-water emulsions. Journal of Membrane Science 500, 211-224.

Ulbricht, M. (2006) Advanced functional polymer membranes. Polymer 47(7), 22172262.

van Oss, C.J. (1993) Acid - base interfacial interactions in aqueous media. Colloids and Surfaces A: Physicochemical and Engineering Aspects 78, 1-49. 
van Oss, C.J. (2006) Interfacial Forces in Aqueous Media, CRC Press, Boca Raton, FL.

van Oss, C.J., Good, R.J. and Chaudhury, M.K. (1988) Additive and nonadditive surface tension components and the interpretation of contact angles. Langmuir 4(4), 884891.

Van Wagner, E.M. (2010) Polyamide desalination membrane characterization and surface modification to enhance fouling resistance. Ph.D. Dissertation, The University of Texas at Austin, Austin, TX.

Vasan, S.S., Bain, C.D., Field, R.W. and Cui, Z. (2006) A Maxwell-Stefan-DerjaguinGrahame model of the concentration profile of a charged solute in the polarisation layer. Desalination 200(1), 175-177.

Vigneswaran, S. and Kwon, D.-Y. (2014) Effect of ionic strength and permeate flux on membrane fouling: Analysis of forces acting on particle deposit and cake formation. KSCE Journal of Civil Engineering, 1-8.

Vigneswaran, S. and Kwon, D.-Y. (2015) Effect of ionic strength and permeate flux on membrane fouling: Analysis of forces acting on particle deposit and cake formation. KSCE Journal of Civil Engineering 19(6), 1604-1611.

Xiao, K., Wang, X., Huang, X., Waite, T.D. and Wen, X. (2011) Combined effect of membrane and foulant hydrophobicity and surface charge on adsorptive fouling during microfiltration. Journal of Membrane Science 373(1-2), 140-151. 